\title{
Enzyme-linked immunofiltration assay used in the screening of solid supports and immunoreagents for the development of an azinphos-methyl flow immunosensor
}

\author{
J.P.M. Sardinha ${ }^{\mathrm{a}, *}$, M.H. Gil ${ }^{\mathrm{a}}$, Josep V. Mercader ${ }^{\mathrm{b}}$, Angel Montoya ${ }^{\mathrm{b}}$ \\ ${ }^{a}$ Departamento de Engenharia Química da Universidade de Coimbra, Polo II, Pinhal de Marrocos, 3030-290 Coimbra, Portugal \\ ${ }^{\mathrm{b}}$ Laboratorio Integrado de Bioingeniería, Universidad Politécnica de Valencia, Camino de Vera s/n, 46022 Valencia, Spain
}

Received 25 April 2001; received in revised form 17 October 2001; accepted 17 October 2001

\begin{abstract}
Azinphos-methyl (AM), $O, O$-dimethyl $S$-[(4-oxo-1,2,3-benzotriazin-3(4H)-yl)methyl] phosphorodithioate, is a dithiophosphorous insecticide extensively used for the control of fruit culture pests. In this work the ELIFA system, initially developed and marketed to substitute conventional ELISA methods, was used for the screening of supports and immunoreagents in the development of a flow immunosensor to AM. The objective was to find the optimal antibody concentration, support quantity and enzymatic tracer concentration to develop a sensitive and reusable immunosensor. The influence of chitosan as protein stabilizing agent was also investigated. We observed that, on the basis of immunosorbent characterization, chitosan-modified silica with immobilized LIB-MFH14 monoclonal antibody (MAb) showed the best sensitivity, with a $I_{50}$ value of $6 \mathrm{nM}$ AM. All of the immobilized MAbs either in alkylaminated or chitosan-modified silica showed $I_{50}$ values between 10 and $36 \mathrm{nM}$. Regarding the regeneration capability, the best desorption agent tested was $0.1 \mathrm{M}$ glycine/ $\mathrm{HCl}, \mathrm{pH} 2.0$, performing in most cases a $100 \%$ desorption after just one wash and maintaining the antibody activity even after 20 cycles of regeneration. The chitosan-modified silica seemed to be the best support for this purpose. (C) 2002 Elsevier Science B.V. All rights reserved.
\end{abstract}

Keywords: ELIFA; Azinphos-methyl; Chitosan; Immunofiltration; Silica powder

\footnotetext{
Abbreviations: ELIFA, enzyme-linked immunofiltration assay; ELISA, enzyme-linked immunosorbent assay; MAb, monoclonal antibody; $I_{50}$, analyte concentration for $50 \%$ maximum response; AM, azinphos-methyl; BSA, bovine serum albumin; OPD, ophenylenediamine; HRP, horseradish peroxidase; PBS, phosphate buffer saline (10 mM phosphate, $137 \mathrm{mM} \mathrm{NaCl}, 2.7 \mathrm{mM} \mathrm{KCl}, \mathrm{pH}$ 7.4); PBST, PBS containing $0.05 \%$ tween 20 ; APTS, (3-aminopropyl)triethoxysilane; TGA, thermogravimetric analysis.

* Corresponding author. Tel.: +351-239-798743; fax: +351239-798703.

E-mail address: jopamasa@ci.uc.pt (J.P.M. Sardinha).
}

\section{Introduction}

The exponential growth of human population in the last 50 years has led to the indiscriminate use of pesticides. Most of the 2.5 millions of tons of pesticides (Van der Werf, 1996) used worldwide per year are being kept in the environment and exposing directly or indirectly several species. This phenomena can affect the ecologic balance of nature, producing resistant species and the subsequent appearance of new pests. Chemical contamination also directly affects the human health, which has sparked off more 
restrictive regulatory laws for environmental control, specially for water and food quality (Barceló, 1993; Bilitewski, 2000).

The need of a continuous monitoring of several pollutants, has increased the development of new techniques for their detection and control. Immunochemical methods are considered as a good alternative to the expensive classical chromatographic analysis (Sherma, 1993; Bernard et al., 2001). Immunoassays for pesticides and other contaminants have been reviewed recently by Meulenberg (1997) and Schobel et al. (2000). Monoclonal antibody technology is virtually able to produce antibodies against any organic molecule, thus allowing the development of immunosensor devices based on automated immunochemical methods. Flow-injection methodologies are usually applied using labelled reagents and a solid phase to immobilize either the antibody or the antigen, permitting the separation of free fractions from immunocomplexes (Puchades et al., 1992; Trau et al., 1997; Uithoven et al., 2000).

In order to be a competitive analytical device, an immunosensor must display a low detection limit, a large dynamic range and, if possible, it should be reusable. Several parameters contribute for the immunosensor performance, being the support and the applied immobilization procedure fundamental choices. The particle size, the pore size diameter, the available surface area and the immobilization method (oriented or not oriented) are important factors that contribute to a better understanding of immunosensors performance.

Silica powder has been used as support for the immobilization of biomolecules (Ernest-Cabrera and Wilchek, 1986; Ghous and Townshend, 1999). The flow properties of this material make it a suitable solid phase for the development of flow immunosensors. The optimization of immunochemical conditions for flow immunosensors has already been addressed using a rapid screening technique based on the enzyme-linked immunofiltration assay (ELIFA) (Morais et al., 1997). Searching for maximum sensitivity and reusability, different combinations of immunosorbent conditions and tracer concentrations can be compared by means of this procedure, thus permitting the choice of the most adequate immunochemical conditions. This screening procedure cannot be carried out by using an ELISA, since it is absolutely necessary to have a filtration compartment in order to prevent the leakage of the immunosorbent.

The aim of this work was to evaluate the suitability of modified silica materials as supports for the development of a flow immunosensor for the detection of the insecticide azinphos-methyl [AM, $O, O$-dimethyl $S$-[(4-oxo-1,2,3-benzotriazin-3(4H)-yl)methyl] phosphorodithioate], a dithiophosphorous compound extensively used for the control of fruit culture pests. Three monoclonal antibodies (MAbs) against AM and two supports (alkylaminated silica and chitosan-modified silica) were used. The unspecific adsorption of immunochemicals is a common problem in solidphase immunoassays, mainly in indirect assays where a macromolecular protein complex between the primary antibody and a secondary labelled antibody can strongly interact with the support. Based on that, the direct assay format with immobilized MAbs was chosen and applied through this study. However, in the direct assay format, the majority of the MAbs loses their recognition properties when the antigen is dissociated from the antigen-antibody complex (Beyer et al., 1995). Accordingly, the support was modified with chitosan in order to estimate if there is an improvement on the remaining activity of the immobilized MAbs after dissociation of the immunocomplex.

\section{Materials and methods}

\subsection{Immunoreagents, chemicals and apparatus}

Analytical grade azinphos-methyl standard was purchased from Riedel-de-Haen (Seelze, Germany). From this stock, working standards (10,000 nM to $240 \mathrm{pM})$ were prepared by appropriate serial dilutions in dry dimethylformamide. Haptens MFH (6- $(N$-phtalimidoylmethyltio) hexanoic acid) and MBH (6-[(4-Oxo1,2,3-benzotriazin-3-yl)methyltio] hexanoic acid), as well as the three anti-azinphos-methyl MAbs (LIBMFH 13, LIB-MFH 14 and LIB-MFH 110) were previously prepared and characterized by ELISA (Mercader and Montoya, 1999a,b). Hapten structures are shown in Fig. 1. Bovine serum albumin (BSA), ophenylenediamine (OPD), and Tween 20 were from Sigma (St. Louis, MO). Horseradish peroxidase (HRP) was obtained from Boehringer (Mannheim, Germany). All of the other reagents were of analytical grade. The 
<smiles>COP(=S)(OC)SCn1nnc2ccccc2c1=O</smiles>

Structure of azinphos- methyl<smiles>CCCCCCCCCCCCC(=O)O</smiles>

MFH hapten<smiles>CCCCn1nnc2ccccc2c1=O</smiles>

MBH hapten

Fig. 1. Structure of azinphos-methyl and schematic representation of the immunizing hapten (MFH) and the assay hapten (MBH).

phosphate-buffered saline (PBS) was $10 \mathrm{mM}$ phosphate, $137 \mathrm{mM} \mathrm{NaCl}, 2.7 \mathrm{mM} \mathrm{KCl}, \mathrm{pH}$ 7.4. The (3aminopropyl) triethoxysilane (APTS) was supplied by Fluka. Nucleosil (particle size of $25-40 \mu \mathrm{m}$ with a pore diameter of $100 \mathrm{~nm}$ ) was purchased from MachereyNagel (Duren-Germany). The ELIFA device was acquired from Pierce Chemical Company (Rockford, IL). The flow-rate was controlled by a one-channel peristaltic pump (Gilson, Villiers LeBel, France). Polystyrene 96-well microtiter plates were obtained from Costar, Cambridge, MA (high binding plates, catalogue no. 3590). The absorbance values were read in a dualwavelength mode (490-650 nm) with a Dynatech MR700 microplate reader (Sussex, UK). The ultraviolet-visible (UV-VIS) spectra were recorded on a UV 160A Shimadzu spectrophotometer (Kyoto, Japan).

\subsection{Preparation of $M B H-H R P$ conjugate}

For direct assays, a MBH-HRP enzyme tracer was prepared by the active ester method (Langone and Van
Vunakis, 1975). The hapten (initial hapten-to-protein molar ratio of 20) was left to react overnight with an excess of $N, N^{\prime}$-dicyclohexylcarbodiimide and $N$ hydroxisuccinimide at $25{ }^{\circ} \mathrm{C}$, in the dark. The obtained suspension was centrifuged and the supernatant containing the active ester was collected. Then, the active ester $(0.9 \mu \mathrm{mol})$ was added to $1 \mathrm{ml}$ of HRP solution $(0.045 \mu \mathrm{mol})$ in $50 \mathrm{mM}$ bicarbonate buffer $\mathrm{pH}$ 9.6, and left to react for $2 \mathrm{~h}$ at $25^{\circ} \mathrm{C}$ with gentle stirring. The solution was gel-filtered on a Sephadex G-50 column previously equilibrated with PBS. The final hapten-to-protein molar ratio in the MBH-HRP conjugate was estimated from the absorbance values at $280 \mathrm{~nm}$ and $402.5 \mathrm{~nm}$, by assuming that the molar absorptivities of the hapten and the enzyme were the same for the free and the conjugated forms. The conjugate was diluted in an equal volume of a saturated ammonium sulphate solution, perfused with an argon flow for $15 \mathrm{~min}$ and stored at $4{ }^{\circ} \mathrm{C}$ until required.

\subsection{Modification of supports (immunosorbents)}

\subsubsection{Alkylamination}

Nucleosil was dried for $2 \mathrm{~h}$ at $120{ }^{\circ} \mathrm{C}$. The silanization procedure was performed by suspending the porous silica $(20 \% \mathrm{w} / \mathrm{v})$ in a $10 \%$ solution of APTS in dry toluene, under nitrogen atmosphere. The reaction was carried out for $48 \mathrm{~h}$ at $37^{\circ} \mathrm{C}$ in a platform shaker. The modified silica was then washed with toluene, methanol and water and finally dried at 100 ${ }^{\circ} \mathrm{C}$ for $18 \mathrm{~h}$.

\subsubsection{Modification of the alkylaminated silica with chitosan}

Two grams of chitosan were dissolved in $20 \mathrm{ml}$ of $50 \mathrm{mM} \mathrm{HCl}$. Any insoluble residue was separated from the solution, by filtration. The chitosan solution was neutralized with $0.1 \mathrm{M} \mathrm{NaOH}$ until $\mathrm{pH}$ 6.0. A suspension of the alkylaminated silica $(10 \% \mathrm{w} / \mathrm{v})$ was treated, in dry dimethylsulfoxide (DMSO) containing $3 \%$ 1,5-bis(succinimidooxycarbonyloxy) pentane, for $5 \mathrm{~h}$ at $25^{\circ} \mathrm{C}$. Then the silica was filtered and washed thoroughly with DMSO and water. The activated silica was added to the chitosan solution and left to react for $18 \mathrm{~h}$ at $25^{\circ} \mathrm{C}$. Finally, the modified silica was filtered and washed thoroughly with distilled water 
and $50 \mathrm{mM} \mathrm{HCl}$, and dried at $60{ }^{\circ} \mathrm{C}$, until constant weight.

\subsection{Physical characterization of the support}

The percentage of alkylamination of the silica was estimated from the weight loss in a TGA (thermogravimetric analysis) apparatus. The surface area measurements were performed by gas adsorption (nitrogen) using the ASAP (accelerated surface area and porosimetry) instrument. Pore size determination was performed by mercury intrusion/extrusion by using a Micromeritics Poresizer 9320 Mercury porosimeter. All this methodology is very well described by Ramos et al. (1998).

\subsection{Purification and immobilization of monoclonal antibodies}

The three monoclonal antibodies used were stored in a 50\% saturated ammonium sulphate solution until use. After centrifugation at $12000 \times \mathrm{g}$ for $20 \mathrm{~min}$, the clear supernatant was removed. The spectophotometric measurement of the supernatant at $280 \mathrm{~nm}$ showed that no protein was present. The pellet was redissolved in $100 \mathrm{mM}$ acetate buffer, pH 5.5 (oxidation buffer). In order to remove the ammonia salt, the MAb solution was dialised overnight against acetate buffer. The MAb oxidation was performed by adding freshly prepared $100 \mathrm{mM}$ sodium periodate to each MAb solution (1:10 volumetric ratio) and incubating the mixture for $1 \mathrm{~h}$ at room temperature in the dark. The unreacted sodium periodate was quickly removed by gel-filtration on a Sephadex G-25 column, previously equilibrated with $50 \mathrm{mM}$ phosphate buffer, $\mathrm{pH} 8.0$. The collected oxidized MAb was incubated at $25{ }^{\circ} \mathrm{C}$ with the polysaccharide-modified alkylaminated silica powder, in a platform shaker, for $18 \mathrm{~h}$. The MAb concentration was $2.5 \mathrm{mg} / \mathrm{g}$ of modified silica powder. After the coupling reaction was completed, the immunosorbent was washed with PBS. The extent of MAb immobilization was estimated spectrophotometrically by measuring the absorbance values $(280 \mathrm{~nm})$ of the $\mathrm{MAb}$ solution before and after coupling. The reaction yield was between $40 \%$ and $60 \%$. Finally, the silica with covalently linked MAb was resuspended $(50 \mathrm{mg} /$ $\mathrm{ml}$ ) in PBS containing $0.02 \% \mathrm{NaN}_{3}$ and stored at $4{ }^{\circ} \mathrm{C}$ until use.

\subsection{The ELIFA device}

The screening of immunoreagents and supports was based on the use of the ELIFA system. This apparatus is basically composed of a 96-well sample application plate, a 96-transfer cannula set and a collection chamber, which are sealed with two silicone gaskets, to provide constant flow rates in all of the wells. An inert glass fibre membrane (GF/A from Whatman International) was placed over the two gaskets in order to retain the porous silica in the 96well application plate, which was clamped on top of the membrane. The vacuum valve of the device was connected to a peristaltic pump to provide a constant vacuum which pulled the reagents through the membrane and the 96 cannulae, at a given flow rate, into the collection chamber. To prevent non-specific binding of immunoreagents, $200 \mu \mathrm{l}$ of a $1 \%$ BSA in PBS was added to each well, incubated for $10 \mathrm{~min}$ and left to flow through the membrane. Then, $100 \mu \mathrm{l}$ of immunosorbent suspension containing $0.05-1 \mathrm{mg}$ of immunosorbent was placed in each well. By selecting the appropriate flow rate of the vacuum pump, all of the wells were emptied simultaneously in approximately $5 \mathrm{~min}$.

\subsection{Direct non-competitive assays}

After blocking the non-specific binding sites with BSA, $200 \mu \mathrm{l}$ of the MBH-HRP solution was added and filtered through the immunosorbent, followed by five washing steps with $200 \mu$ of PBST (PBS containing $0.05 \%$ Tween 20 ). The ELIFA system was then opened and a microtiter plate was held in the lower chamber. From a freshly prepared substrate solution $\left(2 \mathrm{mg} / \mathrm{ml}\right.$ OPD and $0.013 \% \mathrm{H}_{2} \mathrm{O}_{2}$ in 25 $\mathrm{mM}$ citrate, $62 \mathrm{mM}$ phosphate buffer, $\mathrm{pH} 5.4), 100$ $\mu \mathrm{l}$ was added to each well. The enzyme reaction was stopped after $10 \mathrm{~min}$ by adding $100 \mu \mathrm{l}$ of $2.5 \mathrm{M}$ $\mathrm{H}_{2} \mathrm{SO}_{4}$. The coloured solutions formed were collected in the wells of a microtiter plate and taken away for absorbance measurement at $490 \mathrm{~nm}$.

\subsection{Competitive assays}

The protocol was the same as for the non-competitive assays, except that a competition step was established by adding known amounts of azinphos- 
methyl together with the MBH-HRP solution. Each standard dilution was mixed with the MBH-HRP solution just before it was added to the corresponding ELIFA wells (cocktail assay-like conditions). The concentration of azinphos-methyl that inhibited $50 \%$ of the maximum signal ( $I_{50}$ value) was considered to be an estimate of the MAb sensitivity in each assay. Competition curves were mathematically analysed by fitting experimental points to a fourparameter logistic equation (Raab, 1983) using the Softmax Pro software, version 1.02 from Molecular Devices.

\subsection{Immunosorbent regeneration assays}

\subsubsection{Desorption efficiency}

Under the best competition conditions, the immunosupport and the enzymatic tracer were added to the 96-well application plate. The desorption of the antigen from the immobilized MAb was achieved by using $1-5$ cycles $(200 \mu \mathrm{l} / \mathrm{each})$ of the desorbent solution (see legend of Fig. 2). At the end of each cycle the wells were washed with $200 \mu \mathrm{l}$ of PBST and the remaining $\mathrm{MBH}-\mathrm{HRP}$ was measured. The desorption efficiency percentage (DE) of the different desorbents used was calculated according to Eq. (1):

$\mathrm{DE}=\left(1-A / A_{0}\right) \times 100$

where $A_{0}$ represents the absorbance value obtained by applying no desorption step and $A$ represents the signal obtained when the desorbent solution was added to the bound antigen-MAb complex. For each $\mathrm{MAb}$, the enzyme tracer concentrations giving absorbance values around 1.0 were considered as optimum.

\subsubsection{Remaining activity after regeneration}

The remaining activity of immunosorbents was calculated according to Eq. (2):

Remaining activity $=A / A_{0} \times 100$

where $A$ represents the absorbance value obtained by measuring the enzymatic activity of the bound antigen-MAb complex after immunosorbent regeneration, and $A_{0}$ represents the signal obtained by measur- ing the enzymatic activity of the bound antigen $-\mathrm{MAb}$ complex before any regeneration step.

\section{Results and discussion}

\subsection{Characterization of supports}

The porous silica to be used as support for antibody immobilization was previously characterized by determining the percentage of alkylamination (yield of grafting by thermogravimetric analysis, TGA), the pore size (mercury porosimetry determination) and the surface area (adsorption of $\mathrm{N}_{2}$ ) available for covalent linkage. In fact, the yield of biological immobilization is directly dependent on the number of reactive groups present in the support, which also depends on the available surface area. A very important parameter is the pore size diameter, which influences the access of the biological compound to the inner part of the porous material. From this characterization a bimodal distribution of pore sizes was detected by mercury porosimetry (Ramos et al., 1998). These authors found that the mean pore diameter of $100 \mathrm{~nm}$ indicated by the manufacturer lacks any physical meaning since, in fact, the sample presented two peaks at 13 and $120 \mathrm{~nm}$, respectively. The remaining question was to know which percentages of pores were macropores. From nitrogen adsorption analysis, $16 \mathrm{~m}^{2}$ was calculated as the surface area per gram of silica powder, instead of $25 \mathrm{~m}^{2}$ supplied by the manufacturer. This reduced surface area available for silanization was in agreement with the low yield of grafting based on the TGA, 2\% (w:w). In theoretical terms it corresponded to 227 $\mu \mathrm{mol}$ of amine groups per gram of silica, available for conjugation.

\subsection{Determination of optimum concentrations of immunoreagents}

Once the immunosorbents were prepared by MAb immobilization on the porous silica, optimum concentrations of the reagents (immunosorbent and enzyme tracer) for competitive assays were determined by checkerboard titration in the absence of analyte. Those reagent combinations that gave assay signals around $0.8-1.2$ absorbance units at $490 \mathrm{~nm}$ 

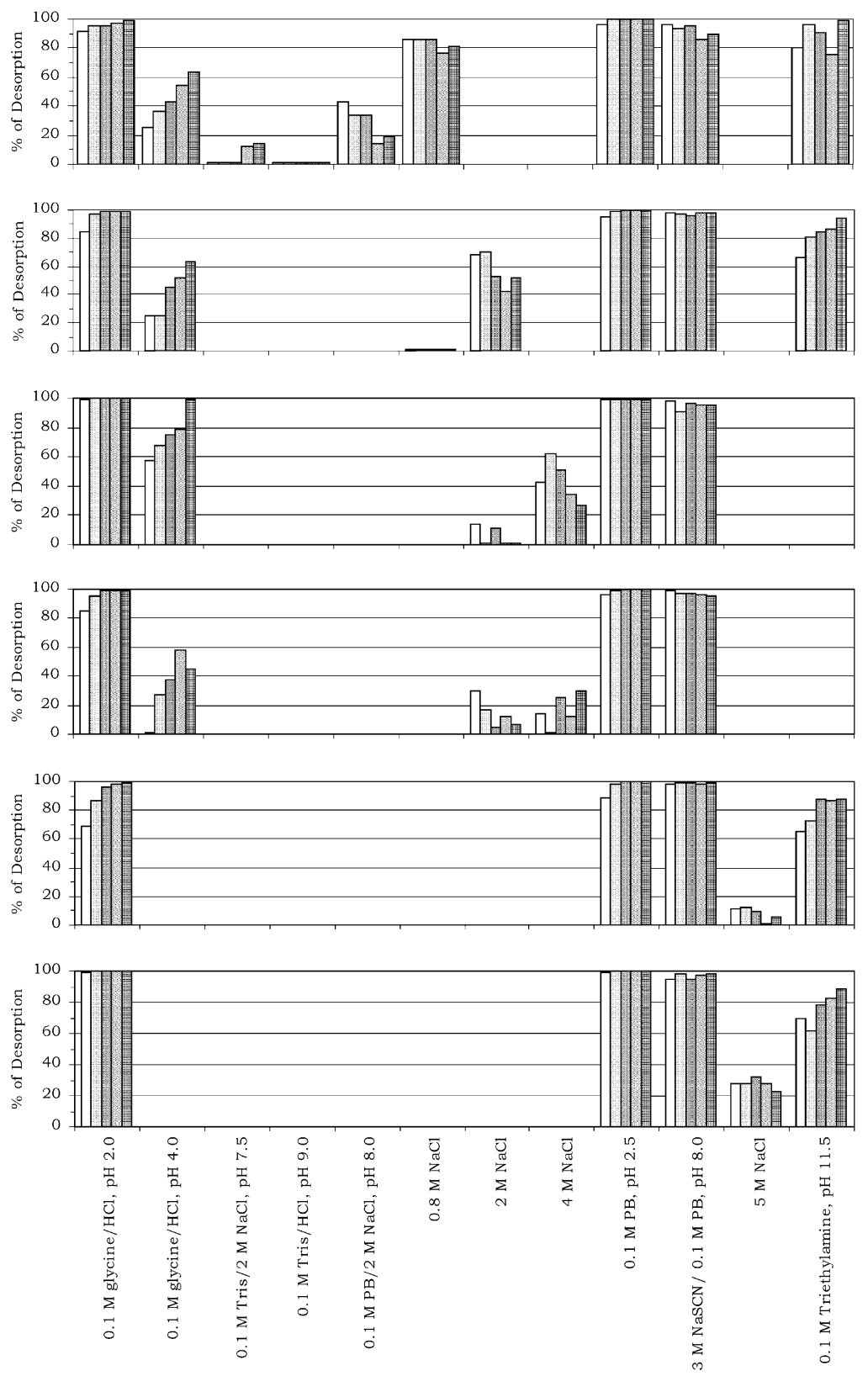

Fig. 2. Percentage of desorption, promoted by several desorbent reagents, of the complex between MBH-HRP and the immobilized antibodies in different supports. From top to bottom: S-MFH13; S-MFH14; S-MFH110; S-Chit-MFH13; S-Chit-MFH14; S-Chit-MFH110. Each set of desorption was performed by five consecutive washes, indicated in the figure by different pattern bars. From the left to the right, first to fifth regeneration cycles, respectively. The desorption solutions were: (A) $0.1 \mathrm{M}$ glycine/HCl, $\mathrm{pH} 2.0$; (B) $0.1 \mathrm{M}$ glycine $/ \mathrm{HCl}$, pH 4.0; (C) $0.1 \mathrm{M}$ Tris/2 M NaCl, pH 7.5; (D) 0.1 M Tris/HCl, pH 9.0; (E) 0.1 M phosphate buffer/2 M NaCl, pH 8.0; (F) $0.8 \mathrm{M} \mathrm{NaCl}$; (G) $2 \mathrm{M} \mathrm{NaCl}$; (H) $4 \mathrm{M}$ $\mathrm{NaCl}$; (I) $0.1 \mathrm{M}$ phosphate buffer, $\mathrm{pH} 2.5$; (J) $3 \mathrm{M} \mathrm{NaSCN}$ in $0.1 \mathrm{M}$ phosphate buffer, $\mathrm{pH} 8.0$; (L) $5 \mathrm{M} \mathrm{NaCl}$; (M) $0.1 \mathrm{M}$ triethylamine, pH 11.5 . 
were first considered as appropriate. On the basis of previous data from ELISA measurements with the same MAbs, we knew that all of the three antibodies recognized very well the analyte as well as the enzyme-labelled hapten. Therefore, the required concentrations for competitive assays should be small. From the checkerboard titration, the most suitable concentrations of immunoreagents were $0.5 \mathrm{mg}$ of MAb-coupled support in combination with $0.01 \mu \mathrm{g} / \mathrm{ml}$ of the enzyme tracer, or $0.1 \mathrm{mg}$ of immunosorbent with $0.05 \mu \mathrm{g} / \mathrm{ml}$ of the enzyme tracer, for any of the three MAbs immobilized in both the alkylaminated silica or the chitosan-modified silica. Azinphosmethyl standard curves were then performed using all of the possible combinations of immobilized MAb, immunosupport and reagent concentrations. Table 1 shows the standard curve fit to the four-parameter logistic equation. The ratio of the maximum absorbance to the corresponding $I_{50}$ value $\left(A_{\max } / I_{50}\right)$ was adopted as the criterion to choice the best conditions for competition. Accordingly, the combination of 0.1 $\mathrm{mg}$ of immunosorbent and $0.05 \mu \mathrm{g} / \mathrm{ml}$ of MBH-HRP conjugate was chosen as the optimum immunoreagent concentrations. As shown, the sensitivity of each immobilized MAb was not dependent on the support used. In fact, the modification of silica powder with chitosan had no important effect on the behaviour of the three MAbs in terms of sensitivity, since for every combination of immunoreagents all of the $I_{50}$ values were in a narrow range $(13-36 \mathrm{nM}$ for the $0.5: 0.01$ combination and 5-21 nM for the 0,1:0,05 combination). Therefore, we can conclude that the treatment with the polysaccharide does not improve the capacity of the MAbs to recognize the conjugated hapten and the analyte; nevertheless, they can perform some protective effects on the operational and storage stability of proteins, as described previously (Villalonga et al., 1999).

\subsection{Regeneration of immunosorbents}

Immunosorbent regeneration, i.e., dissociation of the antigen-antibody complex, plays a key role in order to provide a reusable immunosensor. Solutions with extreme $\mathrm{pH}$ values and/or high salt concentrations are normally employed for that purpose, but they often cause serious damage to the antibody structure. Different reagents for MAb regeneration, such as chaiotropic salts $(\mathrm{NaSCN})$, high salt concentration and buffers with extreme $\mathrm{pH}$ values, were tested to dissociate the antigen-antibody complex. In Fig. 2, the desorption effectiveness of the tested solutions is

Table 1

Standard competition curve parameters for the immobilized MAbs

\begin{tabular}{|c|c|c|c|c|c|c|}
\hline \multirow[t]{2}{*}{ Immunosorbent $^{\mathrm{a}}$} & \multirow{2}{*}{$\begin{array}{l}\text { Support (mg/well): } \\
\text { MBH-HRP }(\mu \mathrm{g} / \mathrm{ml}) \\
\text { combination }\end{array}$} & \multicolumn{3}{|c|}{ Curve parameters ${ }^{\mathrm{b}}$} & \multirow[t]{2}{*}{$\mathrm{CFA}^{\mathrm{c}}\left(R^{2}\right)$} & \multirow[t]{2}{*}{$A_{\max } / I_{50}$} \\
\hline & & $A\left(A_{\max }\right)$ & $B$ & $C\left(I_{50}\right)$ & & \\
\hline \multirow[t]{2}{*}{ S-MFH13 } & $0.5: 0.01$ & 0.594 & 0.704 & 15.049 & 0.984 & 0.039 \\
\hline & $0.1: 0.05$ & 0.511 & 0.924 & 10.854 & 0.977 & 0.047 \\
\hline \multirow[t]{2}{*}{ S-Chit-MFH13 } & $0.5: 0.01$ & 1.079 & 1.018 & 33.887 & 0.987 & 0.032 \\
\hline & $0.1: 0.05$ & 0.971 & 1.149 & 21.025 & 0.994 & 0.046 \\
\hline \multirow[t]{2}{*}{ S-MFH14 } & $0.5: 0.01$ & 1.481 & 0.898 & 30.058 & 0.996 & 0.050 \\
\hline & $0.1: 0.05$ & 1.245 & 0.632 & 16.195 & 0.997 & 0.077 \\
\hline \multirow[t]{2}{*}{ S-Chit-MFH14 } & $0.5: 0.01$ & 0.853 & 1.095 & 13.652 & 0.979 & 0.063 \\
\hline & $0.1: 0.05$ & 0.846 & 0.752 & 5.991 & 0.998 & 0.141 \\
\hline \multirow[t]{2}{*}{ S-MFH110 } & $0.5: 0.01$ & 0.935 & 0.999 & 16.039 & 0.978 & 0.058 \\
\hline & $0.1: 0.05$ & 0.743 & 1.047 & 12.173 & 0.993 & 0.061 \\
\hline \multirow[t]{2}{*}{ S-Chit-MFH110 } & $0.5: 0.01$ & 0.845 & 1.118 & 36.663 & 0.978 & 0.023 \\
\hline & $0.1: 0.05$ & 0.864 & 0.818 & 17.479 & 0.986 & 0.049 \\
\hline
\end{tabular}

a S: alkylaminated nucleosil. Chit:chitosan. MFH13, -14 and -110 designate the immobilized monoclonal antibodies.

b The four-parameters equation used for curve fit was: $Y=\left\{(A-D) /\left[1+(x / C)^{B}\right]\right\}+D . A$ : maximum absorbance value, $B$ : slope at the inflexion point, $C: x$ value at the inflexion point $\left(I_{50}\right.$ value, $\left.\mathrm{nM}\right), D$ : minimum absorbance value.

c CFA: curve fit accuracy $\left(R^{2}\right)$. 
shown. Although several reagents showed some dissociation activity, many of them had only a partial effect, such as salt solutions, Tris and phosphate buffers at medium $\mathrm{pH}$ values. In these cases, $100 \%$ desorption was not reached even after five regeneration cycles. From an overall analysis of the regeneration assays it was quite obvious that the best choices for antibody regeneration were the buffer solutions at low $\mathrm{pH}$, such as $0.1 \mathrm{M}$ phosphate buffer, $\mathrm{pH} 2.5$ and $0.1 \mathrm{M}$ glycine $/ \mathrm{HCl}, \mathrm{pH} 2.0$, or the chaiotropic $3 \mathrm{M}$ $\mathrm{NaSCN}$ solution tested. In these situations, $100 \%$ desorption was achieved after two or three washes. However, these solutions may be too aggressive for protein structure and functionality, which could seriously jeopardize the actual possibilities of reusing the immunosorbents. Accordingly, the next step was to examine if, after desorption, the regenerated MAbs were still able to recognize and bind their target antigens. The remaining activity of immunosorbents was estimated as their ability to recognize the enzyme tracer (Eq. (2)).

For each set of regeneration cycle, a blank was established in order to disrupt the antigen-antibody complex. This control enables us to be sure that the desorption agent is still $100 \%$ effective, which means that no MBH-HRP is adsorbed on the application plate blank after the set of regeneration cycle.
As it can be observed in Table 2, some immunosorbents lost their native activity even after the first regeneration cycle with $\mathrm{NaSCN}$. As mentioned earlier, the immobilized MAbs can lose their hapten recognition properties during the desorption process, as a consequence of the denaturing effect of the regenerating agents used. On the contrary, the three MAbs retained their fully native hapten binding capacity for more than five regeneration cycles when glycine $/ \mathrm{HCl}$, $\mathrm{pH} 2.0$ was used as dissociating reagent for immunocomplexes. Particularly, the immunosorbents prepared with MFH110 could be used until 20 cycles without loss of activity. These results are in agreement with those previously reported for the development of a flow immunosensor to carbaryl using the ELIFA device as a screening tool (Morais et al., 1997). The effectiveness of the glycine desorption is independent from the support, since all the immobilized monoclonal antibodies, either in the presence or absence of chitosan, exhibit a very good remaining activity. Nevertheless, the results are not conclusive about the chitosan stabilization effect since the MFH110 MAb exhibit identical remaining activities, with and without silica modification, after 20 regeneration cycles with glycine.

If we compare the $I_{50}$ values obtained by ELISA by Mercader and Montoya (1999a), 2.0, 4.8 and $1.7 \mathrm{nM}$,

Table 2

Remaining activity of the immunosorbents (\%)

\begin{tabular}{|c|c|c|c|c|c|c|c|c|}
\hline \multirow[t]{4}{*}{$\mathrm{NRC}^{\mathrm{a}}$} & \multicolumn{8}{|c|}{ Immunosorbent $^{\mathrm{b}}$} \\
\hline & \multicolumn{3}{|c|}{ S-MFH110 } & \multicolumn{3}{|c|}{ S-Chit-MFH110 } & \multirow[t]{2}{*}{ S-Chit-MFH13 } & \multirow[t]{2}{*}{ S-MFH14 } \\
\hline & \multicolumn{6}{|c|}{ Desorbent reagent } & & \\
\hline & $\begin{array}{l}\text { Glycine, } \\
\text { pH } 2(1)^{\mathrm{c}}\end{array}$ & $\begin{array}{l}\mathrm{PB}, \\
\mathrm{pH} 2.5 \text { (1) }\end{array}$ & $\begin{array}{l}\text { NaSCN, } \\
3 \mathrm{M}(1)\end{array}$ & $\begin{array}{l}\text { Glycine, } \\
\text { pH } 2 \text { (1) }\end{array}$ & $\begin{array}{l}\mathrm{PB}, \mathrm{pH} \\
2.5(1)\end{array}$ & $\begin{array}{l}\text { NaSCN, } \\
3 \text { M (1) }\end{array}$ & $\begin{array}{l}\text { Glycine, } \\
\text { pH } 2 \text { (3) }\end{array}$ & $\begin{array}{l}\text { Glycine, } \\
\text { pH } 2 \text { (3) }\end{array}$ \\
\hline 1 & 100 & 100 & 69 & 100 & 100 & 74 & 100 & 100 \\
\hline 2 & 100 & 100 & 38 & 100 & 100 & 84 & 100 & 100 \\
\hline 3 & 100 & 100 & 30 & 100 & 100 & 42 & 100 & 100 \\
\hline 4 & 100 & 90 & 18 & 100 & 100 & 27 & 100 & 100 \\
\hline 5 & 100 & 77 & 11 & 100 & 100 & 18 & 100 & 100 \\
\hline 10 & 100 & 60 & n.d. ${ }^{\mathrm{d}}$ & 100 & 96 & n.d. & n.d. & n.d. \\
\hline 20 & 100 & 48 & n.d. & 100 & 93 & n.d. & n.d. & n.d. \\
\hline
\end{tabular}

${ }^{\text {a }}$ NRC: number of regeneration cycles.

${ }^{b}$ S: alkylaminated nucleosil. Chit:chitosan. MFH13, -14 and -110 designate the immobilized monoclonal antibodies.

c The number between parentheses indicates the number of washes with the desorption reagent applied in each regeneration cycle, in agreement with data from regeneration assays.

d n.d.: not determined. 
for the monoclonal antibodies MFH13, MFH14 and MFH110, respectively, with those obtained in this work from ELIFA $\left(I_{50} \mathrm{MFH} 13=15 \mathrm{nM} ; I_{50}\right.$ MFH14 $=30 \mathrm{nM}$ and $I_{50}$ MFH110 $=16 \mathrm{nM}$ ) we can conclude that the immobilized MAb presents a lower affinity for the hapten, as expected. Nevertheless, they still preserve the relative values of $I_{50}$. Moreover, we can observe that the immobilized MAb with the lower affinity (MFH14) needs more washing cycles to recover the full activity, which was unexpected.

\section{Conclusions}

From the described results, the ELIFA system proved to be an adequate technique for the development of flow immunosensors. The appropriate use of this immunofiltration device, as a screening tool, allows that optimum conditions, such as solid phase, immunoreagents and regeneration agents, could be selected for further immunosensor development.

It was proved that the best desorption agent tested was the glycine/ $\mathrm{HCl}$ buffer with a very low $\mathrm{pH}(2.0)$. The dissociation of the tracer hapten from the antibody with this solution does not affect the activity of antibodies, thus allowing at least 20 regeneration cycles. The three anti-azinphos-methyl monoclonal antibodies used displayed very similar characteristics. LIB-MFH14 MAb immobilized onto chitosanmodified silica showed the best sensitivity, with an $I_{50}$ value of around $6 \mathrm{nM}$ for the detection of azinphos-methyl. Nevertheless, LIB-MFH110 MAb exhibited a $100 \%$ regeneration after just one washing step with the glycine buffer, instead of three washing steps needed for the complete regeneration of immobilized LIB-MFH14. Moreover, LIB-MFH110 MAb showed at the same time a very close $I_{50}$ value (around $12 \mathrm{nM}$ ). On the basis of these considerations, further studies will involve the development of a flow immunosensor based on LIB-MFH110 monoclonal antibody, with electrochemical and/or optical detection.

\section{Acknowledgements}

This work was supported by a grant from Fundação para a Ciencia e Tecnologia (Portugal).

\section{References}

Barceló, D., 1993. Environmental protection agency and other methods for determination of priority pesticides and their transformation products in water. J. Chromatogr. 643, 117.

Bernard, A., Michel, B., Delamarche, E., 2001. Micromosaic immunoassays. Anal. Chem. 73 (1), 8.

Beyer, K., Reinecke, M., Noe, W., Scheper, T., 1995. Immunobased elution assay for process control. Anal. Chim. Acta 309 (1-3), 301.

Bilitewski, U., 2000. Can affinity sensors be used to detect food contaminants? Immunoanalytical techniques could provide faster and easier analyses of food products. Anal. Chem. 72 (21), 692A.

Ernest-Cabrera, K., Wilchek, M., 1986. Silica containing primary hydroxyl groups for high-performance affinity chromatography. Anal. Biochem. 159, 267.

Ghous, T., Townshend, A., 1999. Flow injection determination of chlorpromazine by inhibition of glutamate dehydrogenase. Anal. Chim. Acta 387, 47.

Langone, J.J., Van Vunakis, H., 1975. Radioimmunoassay for dieldrin and aldrin. Res. Commun. Pathol. Pharmacol. 10, 163.

Mercader, J., Montoya, A., 1999a. Development of monoclonal ELISAs for azinphos-methyl: 1. Hapten synthesis and antibody production. J. Agric. Food Chem. 47 (3), 1276.

Mercader, J., Montoya, A., 1999b. Development of monoclonal ELISAs for azinphos-methyl: 2. Assay optimization and water sample analysis. J. Agric. Food Chem. 47 (3), 1285.

Meulenberg, E.P., 1997. Immunochemical detection of environmental and food contaminants: development, validation and application. Food Technol. Biotechnol. 35, 153.

Morais, S., Gonzalez-Martinez, M.A., Puchades, R., Montoya, A., Abad, A., Maquieira, A., 1997. A rapid screening of immunoreagents for carbaryl immunosensor, development. In: Immunochemical Technology for Environmental Applications, vol. 657 American Chemical Society, Washington, DC.

Puchades, R., Maquieira, A., Atienza, J., Montoya, A., 1992. A comprehensive overview on the application of flow injection techniques in immunoanalysis. Crit. Rev. Anal. Chem. 23, 301.

Raab, G.M., 1983. Comparison of a logistic and a mass-action curve for radioimmunoassay data. Clin. Chem. 29, 1757.

Ramos, M.A., Gil, M.H., Schacht, E., Matthys, G., Mondelaers, W., Figueiredo, M.M., 1998. Physical and chemical characterisation of some silicas and silicas derivatives. Powder Technol. 99, 79.

Schobel, U., Barzen, C., Gauglitz, G., 2000. Immunoanalytical techniques for pesticide monitoring based on fluorescence detection. Fresenius J. Anal. Chem. 366 (6-7), 646.

Sherma, J., 1993. Pesticides. Anal. Chem. 65, 40R.

Trau, D., Theueri, T., Wilmer, M., Meusel, M., Spener, F., 1997. Development of an amperometric flow injection immunoanalysis system for the determination of the herbicide 2,4-dichlorophenoxyacetic acid in water. Biosens. Bioelectron. 12 (6), 499.

Uithoven, K.A., Schmidt, J.C., Ballman, M.E., 2000. Rapid identification of biological warfare agents using an instrument em- 
ploying a light addressable potentiometric sensor and a flowthrough immunofiltration-enzyme assay system. Biosens. Bioelectron. 14, 761.

Van der Werf, H.M.G., 1996. Assessing the impact of pesticides on the environment. Agric. Ecosyst. Environ. 60, 81.
Villalonga, R., Gómez, L., Ramirez, H.L., Villalonga, M.L., 1999. Stabilization of $\alpha$-amilase by chemical modification with carboxymethylcellulose. J. Chem. Technol. Biotechnol. 74 (7), 635 . 